\title{
The Current Status of Master of Engineering Degree Programs in China: Analysis and Suggestions
}

\author{
Huiying Song, Lingxiang Huang \\ ${ }^{1}$ The School of Geology and Geomatics, Tianjin Institute of Urban Construction, Tianjin, China \\ ${ }^{2}$ The School of Economics and Management, Tianjin Institute of Urban Constructionk, Tianjin, China \\ Email: baobaoshy@163.com,nkhlx@yahoo.com.cn
}

Received 2012

\begin{abstract}
In recent years, with the rapid development of economy and the continuous advancement of technology, the demand for high-level talents with expertise has been gradually increased in China. Master of Engineering (ME), the new education mode, has been developed rapidly. After briefing the status quo of the ME degree programs at home and abroad, this paper examines the current status of Master of Engineering degree programs in China from four aspects, namely the curriculum planning, graduation requirements, mentor qualities and the education system, by analyzing the results of a survey conducted in China's universities. After pointing out the problems existed in the ME degree programs, this paper put forward four pieces of corresponding suggestions.
\end{abstract}

Keywords: Master of Engineering; Degree Program; Curriculum Planning; Education

\section{Introduction}

In order to meet the need of China's economic construction and social development, change the situation of relatively simple type of engineering degree andimprovethe degree system with Chinese characteristics [1], the 15th meeting of State Council Academic Degrees Committee examined and passed the "Setting Plan for Master of Engineering degree". Then Master of Engineering (abbreviated ME, M.Eng. or MEng) degree was decided to set up in China in 1997.

ME degree programs focus on capacity-building, providing professional and technical personnel and managers who have qualifications in engineering for industrial, mining and construction sectors, especially for large and medium-sized stateowned enterprises. Master of engineering degree is divided into full-time ME degree and GCT ME degree.

The history of developed countries in engineering education indicates: the emergence and development of engineering education is closely related to the historical stage of national industrialization and socio-economic development and in the phase of rapid development in industrialization, the demand of advanced applications for the enterprise and the society is increasing [2]. The development of ME degree programs in China are in accordance with this law. Therefore, this paper explores the shortcomings existed in the ME degree programs in China and put forward suggestions by learning from the advanced experience of western countries, so as to improve the ME degree program which will play a more effective role in China's economic development.

\section{Status Quo of ME Degree Programs at Home and Abroad}

\section{Status Quo of ME Degree Programs Abroad}

ME degree is a professional degree emerged recently in the United States. Generally speaking, studentscan earn the ME degreeby successfully completing a one-year program and those who want to pursue further study are provided with the opportunity to take the Doctor of Engineering degree programs. The curriculum of the ME degree program in U.S. is primarily structural, based on courses, and more emphasis on practical experience. Typically, business training, project designing and industrial internship experience are required for the ME degree instead of dissertation or general examination.

The training aim of the high-level engineering education in Europe is quite clear. "Diploma engineer" system is used widely in Europe, has its fixed registration standard, known as the "FEANI" formula. The general formula is " $\mathrm{B}+3 \mathrm{U}+2 \mathrm{E}+2 \mathrm{~T}$ " (or 1T1U, or 1T1E and so on). In the formula B indicates that it accepts education of high school level for 18 years, 3U indicates a 3-year engineering curriculum teaching, $2 \mathrm{E}$ indicates at least a two-year engineering experience, 2T indicates a twoyear engineering training [3]. It is evident that the European countriesattachgreat importance to the connection between universities and industrial enterprises in order to train the students to be qualified engineers. Breaking the boundaries of the social division, the two parties make concerted effort to cooperate in providing high-level talents in the field of engineering.

In Japan, a proportion of teachers in ME degree programs are specifically required to have professional experiences, preferably in a featured sector. Although both the professional and academic master degree programs require a minimum of 30 credits, the professional ME degree does not require a dissertation [4].

\section{Status Quo of ME Degree Program at Home}

Since the pass of the "Setting Plan for Master of Engineering degree" in 1997, a growing number of colleges in China has developed ME degree programs. To be admitted, one must hold a bachelor degree and have related work experience. In 2009, in order to strengthen innovative ability of MEstudents and im- 
prove the quality of the potential talents, China starts to set up full-time ME degree programs.

MEdegree programs in China lasts 2 to 3 years, containing a series of coursework and a dissertation. The curriculum is designed primarily in line with the engineering field, with emphasis on the broadness of knowledge structure as well as practical ability of operation. Courses of the programs fall into three categories: basic courses, required core courses and elective courses. Teaching methods adopted are phase teaching, concentrated teaching andsub-paragraph scattered digestion. The research subject of the dissertation must be derived from engineering practice, with clear engineering background and application values. In the part-time ME degree programs, students are offered two-on-one mentoring, which means a supervisor from the college and an advisor form the enterprises will work together to help the students put the theories they have learned into practice. Besides, they usually choose the study direction and mentors based on the project they are undertaking in the companies. The full-time ME students, however, have only one mentor from the college and they make their choice by considering their interests of study and future career planning [5].

\section{Empirical Study on ME Degree Programs in China}

With a brief look at the development of ME degree programs home and abroad, the author finds it necessary to further explore China's situation so as to discover the aspects for improvement. To better analyze the curriculum planning, graduation requirements andmentor qualities of ME degree programs in China, the author sent a total of 547 questionnaires to the students who are now taking the ME degree programs in certain universities in Beijing and Tianjin. A total of 478 questionnaires were collected, of which 453 were valid for analysis.

The survey has three parts and the results for questions of each part are shown in Table 1, Table 2 and 3 respectively.

Table 1.

Views on the Curriculum Design.

\begin{tabular}{|c|c|c|c|}
\hline Question & Yes & No & Cannot say \\
\hline Whether the teaching contents are out-dated? & $66 \%$ & $10 \%$ & $24 \%$ \\
\hline $\begin{array}{l}\text { Whether there are plenty of interdisciplinary } \\
\text { courses? }\end{array}$ & $32 \%$ & $48 \%$ & $20 \%$ \\
\hline $\begin{array}{l}\text { Whether theinternetand other high-tech } \\
\text { equipmenthave been properly used? }\end{array}$ & $27 \%$ & $68 \%$ & $5 \%$ \\
\hline
\end{tabular}

Table 2.

Views on Graduation Requirements.

\begin{tabular}{|c|c|c|c|}
\hline Questions & High & Medium & Low \\
\hline Requirements on depth of the study & $74 \%$ & $22 \%$ & $4 \%$ \\
\hline $\begin{array}{l}\text { Requirements on innovative ideas of the } \\
\text { dissertation }\end{array}$ & $25 \%$ & $33 \%$ & $42 \%$ \\
\hline Requirements on feasibility of the research & $28 \%$ & $30 \%$ & $42 \%$ \\
\hline $\begin{array}{l}\text { The strictness ofmid-terminspection and } \\
\text { evaluation }\end{array}$ & $32 \%$ & $26 \%$ & $42 \%$ \\
\hline
\end{tabular}

Table 3.

Views on Mentoring.

\begin{tabular}{lccc}
\hline \multicolumn{1}{c}{ Questions } & Yes & No & Cannot say \\
\hline $\begin{array}{l}\text { Whether the mentors take other responsibilities, } \\
\text { such as teaching, conducting research projects } \\
\text { and taking charge of administrative affairs }\end{array}$ & $99 \%$ & 0 & $1 \%$ \\
$\begin{array}{l}\text { Whether the mentors can provide the students with } \\
\text { constructive suggestionsin engineering practice? }\end{array}$ & $34 \%$ & $56 \%$ & $10 \%$ \\
$\begin{array}{l}\text { Whether the students can get timely advices } \\
\text { and instructions from the mentors? }\end{array}$ & $27 \%$ & $68 \%$ & $5 \%$ \\
\hline
\end{tabular}

Table 1 shows that the current curriculum design is not reasonable, as it seen by the out-dated teaching contents which cannot keep pace with the developments of the courses, its narrow scope with limited interdisciplinary courses and its unpractical teaching standards by which the graduates are trained to be research fellows instead of engineers in great demand in industrial and mining enterprises. Furthermore, while the internet and other high-tech equipment have not been fully utilized as a supplementary means, the students get bored easily with the simple and single teaching method. Reform on the curriculum design and teaching method is urgently needed.

Currently the graduation requirement for ME degree is simply getting a pass in the dissertation; therefore most of the graduates are not able to handle the operation of engineering projects in enterprises due to the lack of practical experience. According to the results shown in Table 2, universities set a high standard for the depth of the dissertation, but a much lower requirement on creativity and feasibility and mid-term inspection and evaluation seems neither strict nor effective. As the universities are provided with autonomy to manage the education of ME, while the society's role of supervising on the education quality has not been brought to full play, we can only rely on the consciousness and the self-discipline of the universities to ensure the education quality of the ME degree programs.

The students' views on mentoring are illustrated in Table 3. The results show no difference between the mentors for Master of Engineering and those for Master of Science, since the ME mentors are neither required to have practical experience in industrial sectorsnorgiven the training opportunity to learn to train "application-type” talents. Nearly all the mentorstake other work responsibilities, including, but not limited to, teaching, conducting research projects and taking charge of administrative affairs. Mentors' lack of time and energy as well as the lack of connection between colleges and enterprises lead to the fact that the students of ME degree programs can't get useful instruction in their research and practice, which means that the mentoring system doesn't produce the expected effect.

\section{Lessions and Suggestions Readjustthe Curriculum of ME Degree Programs}

The current curriculum planning reflects that the programs give priority to impart theoretical knowledge, while ignoring practical skills training. To improve the ME degree programs in China, the coursework should notbe limitedto the existing materials, but focus on situation faced by enterprises. Teachers should elaborate the fundamental theories, technical methods 
and examination methods, especially new knowledge, new technology, and new craft to students, via lecture in classroom, experiment, discussion and seminars. Practical courses can be taught in enterprises. Aiming at help the students gain practical experiences and solve the problem they are facing in enterprises, the curriculum should be designed on the principle of "widening the aperture, highlighting the point and focusing on application". In order to meet the needs of application-oriented talents, colleges should make a specific curriculum planaccording to the "order" for some enterprises and institutions [6].

\section{Reform the Graduation Requirements for ME Degree}

Most ME degree programs abroaddo not require a dissertation for graduation;instead, a practical project design is needed. In this way, after gaining the ME degree, students' knowledge and skills can rapidly transform to enterprise's productive forces, so as to enhance enterprise efficiency. By contrast, all of the Chinese ME students have tocomplete dissertations and pass the defense, without linking the theory to practice. Therefore, the graduation requirements should be reformed. Students can choose to submit a dissertation, a project report, a transformation plan for technical process or other forms of work for graduation evaluation according to their own professional areas and interests. The graduation dissertation or projects should be practice-oriented, instead of only emphasizing on theoretical depth. The most important thing for the students is to grasp the overall operation of the projectand build their expertise in specific field. Thus the graduates with ME degree can take charge of the operation of a project as soon as they join the company and save the cost of personnel training for enterprises.

\section{Enhancethe Quality of the Facultyteam of ME Degree Program}

The teachers of ME degree programs should both have the teaching ability and a wealth of experience in engineering practice. In west countries, most mentors have vocational experience and colleges are even encouragedto employ part-time mentors who work in companies at the same time. To learn from their successful cases, colleges in China should enhancethe quality of the faculty team of ME degree program at three levels. First, teachers, especially young ones should be provided more opportunity for training and participating in the real projects. Colleges should systematically send some young teachers to related companies to take part in research and development of the new products and technical innovation, so as to enrich their work experience.Second, schools should invite outstanding entrepreneurs, senior managers and senior technical staff to give lectures, hold panel discussions and even to be teacherfor the ME degree programs. Last but not least, mentors should be seriously selected and carefully trained, and their responsibilities should be specifies, so as to guarantee the mentoring quality.

\section{Improvethe Education System of Professional Degrees in the Field of Engineering}

In the education system of professional degrees in the field of engineering, ME degree programs and Doctor of Engineering degree programs should not only be established and developed, but also be integrated with the Engineer Diploma building a more close relationship with industries. For example, those with a ME degree should be waived of the theory test and gain the engineer qualification certification after passing the test for operation, while those who have gained doctor degree in engineering could directly process the engineer qualification. The ME degree programs will be more attractive with the implementationof one of the principlesdeclared in "The Interim Measures for Approval of Professional Degree Setting”, which refers to the Clause 10 that "those industrial sectors concerningprofessional degrees should gradually take the professional degrees into consideration as part of preferred qualifications for employment [7].

\section{Conclusion}

This paper starts with an overview of the status quo of ME degree programs in China and abroad and conducted and in-depth analysis from four aspects, namely the curriculum planning, graduation requirements, mentor qualities and the education system, by examining the results of a survey conducted among students taking ME degree programs in China.In order to learn lessons from the successful cases abroad and solve the problems existed in the ME degree programs in China, the author proposed four pieces of suggestions, including readjusting the curriculum, reforming the graduation requirements, enhancing the quality of the faculty team and improving the education system of professional degree in the field of engineering. In the critical moment of China's economic transition, ME degree programs have the most potential in the professional degree education. With the development and improvement of the programs, they will play an increasingly significant role in guaranteeing the successful transition of China's economy and the steady growth in national comprehensive capabilities.

\section{REFERENCES}

State Council Academic Degrees Committee, State Education Commission "Notice on the implementation of the Setting Pan for Master of Engineering”, No.54, 1997

G. Jin, "Development characteristics and its influencing factors in education of Master of Engineering degree”, Education and Vocational, pp. 22-24,November 2011

J. Guan, "Comparative study in Master of Engineering degree educationbetween China and the United States”, Hunan Normal University, dissertation for master degree, 2005.

W. Wang, "Lessonsfrom a comparison of professional master degree education amongChina, Japan and South Korea”,Vocational and Technical Education, pp. 90-93, January 2010

Y. Qiao, “The exploring of graduate training of full-time Master of Engineering degree programs", Science and Technology Information, Vol. 13, pp. 157, January 2010.

$\mathrm{J}$. $\mathrm{Hu}$, "The characteristics of education,problems and solutions in Master of Engineering degree programs”, Culture, History and Philosophy, pp. 120-122, January 2011.

J. Guan, "Comparative study in education system of Master of Engineering between China and the United States”, Higher Education Development and Evaluation, pp. 73-79,February 2011. 